\title{
Lipid Profile of the Patient with Acute Coronary Syndromes Undergoing Coronary Angiography (CAG) in Rural Costal Region of Maharashtra
}

Deshpande Janhavi JAYWANT'', Amit BHALERAO', Vikas RATNAPARKHI', Suryakant NISALE', Pranav SHAMRAJ', Ujjwala KULKARNI', Sunil KOTKUNDE' , Nitin KESARKAR', Sagar NANAWARE', Vikas DEOKAR ${ }^{1}$, Chaitanya MADKAR', Ravi SING ${ }^{\top}$

\begin{abstract}
Background: Coronary Heart Disease (CHD) is widely prevalent across the globe and significantly high level of Cholesterol in circulation is a single major risk factor associated with coronary heart disease. It is well established that cardiovascular disease is associated with hypertension and elevated blood levels of low-density lipoprotein $(\mathrm{LDL})$, total cholesterol, and triglycerides. In disparity, a low level of high-density lipoprotein (HDL) is a risk factor for mortality from cardiovascular disease. Aim: The present study was conducted with the aim to assess the lipid profile in patients of Acute Coronary Syndrome (ACS) undergoing coronary angiography (CAG) in rural coastal population. Patients and Methods: The present study was done on 62 patients with Acute Coronary Syndrome (ACS) undergoing coronary angiography (CAG) Serum levels of total cholesterol, HDL cholesterol, LDL cholesterol, and triglycerides were examined in biochemical laboratory of the hospital. Coronary angiography was performed for the presence of lesions. Results: $43.5 \%$ of the patients ( $n=27$ ) were elderly (age $>60$ years). Approximately $82 \%$ of the patients $(n=51)$ aged more than 50 years. Males outnumbered females with a ratio of $2.4: 1.71 \%$ of the patients were males. Mean cholesterol levels were $177.86 \mathrm{mg} / \mathrm{dl}$. Approx 3/4th of the patients $(\mathrm{n}=41)$ had cholesterol level $<200 \mathrm{mg} / \mathrm{Dl}$. Mean triglycerides levels in the patients were $158.29 \mathrm{mg} / \mathrm{dl}$. Only 11 patients out of 62 CAD patients had abnormal triglycerides. Mean LDL level was $119.5 \mathrm{mg}$ and Mean HDL level was $34.5 \mathrm{mg} \%$. The high plasma concentration of low-density lipoprotein (LDL-C) in 30\% and the low plasma concentration of high-density lipoprotein (HDL-C) n 33\% of patients were important abnormal findings in our patients. Conclusion: Dyslipidemia as in form of very low levels of HDL cholesterol with comparatively high levels of LDL-C with near normal total Cholesterol and triglyceride levels associated with ACS in our rural costal region of Maharashtra.
\end{abstract}

Keywords: coronary heart disease, high-density lipoprotein, low-density lipoprotein, acute coronary syndrome.

'Department of General Medicine B.K.L. Walawalkar Rural Medical College and Hospital, Dervan Dist Ratnagiri, Maharashtra, India
Corresponding author:

Deshpande Janhavi JAYWANT, Department of General Medicine, B.K.L. Walawalkar Rural Medical College and Hospital, Dervan Pin 415606, A/P Sawarde-Kasarwadi, Taluka Chiplun, Dist Ratnagiri, Maharashtra, India.

E-mail: dvjaywant@gmail.com 


\section{INTRODUCTION}

Derangements in lipid profile are one of the best established risk-factors for coronary artery disease (CAD). It is a known fact that CAD in Indians occurs at levels of dyslipidemia much lower than western populations and many Indian patients with CAD have lipid profile that is much lower than their western population ${ }^{1}$.

Excess intake of saturated fatty acids associated with decreased cereals, fruit and vegetables does not only alter the lipid profile but also increases the risk of coronary disease. An elevated total/HDL cholesterol ratio and the presence of lipoprotein constitute significant risk factors for coronary events. On the other hand, high HDL cholesterol levels $(>45 \mathrm{mg} / \mathrm{dl})$ are considered to be protective in women ${ }^{2}$. Diabetes increases the effects of the other risk factors and modifies the protective effect by estrogens ${ }^{2}$. Men and women share some risk factors, including high serum cholesterol levels, adverse lipoprotein profile, smoking, hypertension, diabetes, obesity, advanced age, and according to some studies sedentary lifestyle. Additional factors that may affect women more than men, are elevated serum triglyceride levels, natural or surgical menopause, use of oral contraceptives (OCs), and possibly hormonal substitution therapy ${ }^{3}$. Average total cholesterol and LDL cholesterol are higher in men than in premenopausal women, but women's levels rise after menopause until they eventually exceed those of men. ${ }^{6}$ Several studies have shown that high serum concentrations of total and LDL cholesterol and relatively low levels of HDL cholesterol are correlated with development of atherosclerotic lesions and increased cardiovascular risk in men, and that lowering cholesterol reduces the risk ${ }^{4}$. Many studies have demonstrated that postmenopausal use of estrogens alone result in a decrease in LDL and an increase in HDL levels ${ }^{4}$. The present was aimed to study Lipid profile of the patients with ACS undergoing CAG.

\section{MATERIALS AND METHODS}

A total of 62 patients presented with ACS undergoing CAG during the period of Jan 2019 to June2019 at B.K.L. Walawalkar Rural Medical College and Hospital were included in the study.

\section{DEFINITIONS}

Following investigations were done:

$\square$ Total cholesterol-N- $\leq 220 \mathrm{mg} / \mathrm{dL},->220 \mathrm{mg} / \mathrm{dL}$ as abnormal level;

$\square$ Triglycerides-N- $\leq 160 \mathrm{mg} / \mathrm{dL},->160 \mathrm{mg} / \mathrm{dL}$ as abnormal level;

$\square$ HDL cholesterol- N- up to $35 \mathrm{mg} / \mathrm{dL},-<35 \mathrm{mg} /$ $\mathrm{dL}$ in men and $<40 \mathrm{mg} / \mathrm{dL}$ in women as abnormal level;

LDL cholesterol-N- up to $130 \mathrm{mg} / \mathrm{dL},>130 \mathrm{mg} /$ $\mathrm{dL}$ as abnormal level in non-diabetics \& non hypertensive but abnormal $>100 \mathrm{mg} \%$ in DM or/and hypertension.

\section{DATA ANALYSIS}

Data were presented as frequency, percentage, and mean.

\section{RESULTS}

Table 1 shows that $43.5 \%$ of the patients $(n=27)$ were elderly (age $>60$ years). Approximately $82 \%$ of the patients $(n=51)$ aged more than 50 years. Males outnumbered females with a ratio of $2.4: 1.71 \%$ of the patients were males (Figure 1). Mean cholesterol levels were $177.86 \mathrm{mg} / \mathrm{dl}$. Almost 3/4 of the patients $(\mathrm{n}=41)$ had cholesterol level $<200 \mathrm{mg} / \mathrm{dL}$ (Table 2). Mean triglycerides levels in the patients with CAD were 158.29 $\mathrm{mg} / \mathrm{dl}$. Only 11 patients out of 62 CAD patients had abnormal triglycerides (Table 3). Mean LDL level was $119.5 \mathrm{mg}$ and Mean HDL level was $34.5 \mathrm{mg} \%$.

Table 1. Age-based distribution of patients

\begin{tabular}{|l|c|}
\hline Age-group (Year) & Number of Patients \\
\hline $21-30$ & 1 \\
\hline $31-40$ & 2 \\
\hline $41-50$ & 8 \\
\hline $51-60$ & 24 \\
\hline $61-70$ & 17 \\
\hline $71-80$ & 10 \\
\hline Grand Total & $\mathbf{6 2}$ \\
\hline
\end{tabular}






Figure 1. Sex-based distribution of patients

Table 2. Total cholesterol

\begin{tabular}{|l|c|c|}
\hline Cholesterol Level & $\mathrm{n}$ & $\%$ \\
\hline Normal & 46 & $74 \%$ \\
\hline Abnormal $(>220 \mathrm{mg} / \mathrm{dl})$ & 16 & $26 \%$ \\
\hline
\end{tabular}

Table 3. Serum triglycerides

\begin{tabular}{|l|c|c|}
\hline Triglycerides Level & $\mathrm{n}$ & $\%$ \\
\hline Normal & 51 & $82.25 \%$ \\
\hline Abnormal $(>160 \mathrm{mg} / \mathrm{dl})$ & 11 & $17.75 \%$ \\
\hline
\end{tabular}

\section{DISCUSSION}

Dyslipidemia is an established risk factor for the development of coronary artery disease (CAD), which has been demonstrated through numerous clinical-epidemiological studies ${ }^{5-7}$. The high plasma concentration of low-density lipoprotein (LDL-C) is directly related to the development of coronary artery disease, and the low plasma concentration of high-density lipoprotein (HDL-C) has been identified as one of the strongest factors risk factors for atherosclerotic coronary disease. New evidence indicates that modest increases in triglycerides increase the risk of coronary events and the progression of coronary artery disease, as well as the formation of new lesions ${ }^{8-10}$. Our study observed that the high plasma concentration of low-density lipoprotein (LDL-C) was seen in $30 \%$ of patients and the low plasma concentration of high-density lipoprotein (HDL-C) was detected in 33\% of patients.
Table 4. Serum HDL and LDL

\begin{tabular}{|l|c|c|}
\hline Serum HDL and LDL & $\mathrm{n}$ & $\%$ \\
\hline Abevel & & \\
\hline Abnormal LDL $(>130 \mathrm{mg} / \mathrm{dl})$ & 19 & $30 \%$ \\
\hline
\end{tabular}

A study by Gupta et al at found out that total cholesterol levels were not significantly higher in CAD patients compared to healthy age-matched controls ${ }^{11}$. Patients in our study had similar cholesterol levels i.e. not significantly elevated above normal. However, the above-mentioned comparison is not possible due to absence of healthy subjects in our study.

Another study, of risk factor for CAD in Asian Indians of USA found average LDL cholesterol was $117.8 \mathrm{mg} \%$ \& $119.08 \mathrm{mg} \%$ in our study ${ }^{1}$. This study was conducted on 110 Asian Indian physicians residing in United States. Our results are in concordance with the above-mentioned study.

Pant and Pant studied lipid profile in the patients with myocardial infarction (MI). They found that majority of the patients had normal lipid profile ${ }^{12}$. Our results are in concordance with the above study.

Korhonen et al reported that high LDL levels are associated with an increased risk of $\mathrm{CAD}^{13}$ and our results are in concordance with the above study.

\section{CONCLUSION}

Total cholesterol and triglycerides levels were not significantly deranged in our patients but high plasma concentration of low-density lipoprotein (LDL-C) in $30 \%$ and the low plasma concentration of high-density lipoprotein (HDL-C) n 33\% of patients were important abnormal findings in our patients with CAD. Studies with a larger population are warranted to further validate the association of lipid profile with ACS.

Compliance with ethics requirements: The authors declare no conflict of interest regarding this article. The authors declare that all the procedures and experiments of this study respect the ethical standards in the Helsinki Declaration of 1975, as revised in 2008(5) and the national law. Informed consent was obtained from the patient described in the clinical case and his parents. 


\section{References}

1. Enas A, Yusuf S, Mehta JL. Prevalence of coronary artery disease in Asian Indians. Am J Cardiol 1992;70(9): 945-9

2. Adak M, Shivapuri JN. Serum lipid and lipoprotein profile abnormality in predicting the risk of coronary artery disease in non-diabetic patients attending NMCTH, Birgunj. Nepal Med Coll J 2010;12(3):158-64

3. Rajmohan L, Deepa R, Mohan A, Mohan V, Association between isolated hypercholesterolemia, isolated hypertriglyceridemia and coronary artery disease in south Indian type 2 diabetic patients, Indian. 2000;52(4):400-6.

4. Assmann G, Davignon J, Fernández Cruz A, Gotto AM Jr, Jacotot $\mathrm{B}$, Lewis $\mathrm{B}$, et al. Women and ischemic cardiopathy. Rev Clin Esp. 1989;185(6):308-15

5. Smith SC, Jackson R, Pearson TA, Fuster V, Yusuf S, Faergeman $\mathrm{O}$, et al. Principles for national and regional guidelines on cardiovascular disease prevention: a scientific statement from the heart and stroke forum. Circulation. 2004; 109: 3112-21.

6. Watts GF, Mandalia S, Brunt JNH, Slavin BM, Coltart DJ, Lewis B. Independent associations between plasma lipoprotein subfraction levels and the course of coronary artery disease in the St. Thomas' Atherosclerosis Regression Study (STARS). Metabolism. 1993; 42: 1461-7.
7. Ladeia AM, Guimarães AC, Lima JC. Lipid profile and coronary artery disease. Arq Bras Cardiol. 1994; 63: 101-6.

8. Assmann $\mathrm{G}$, Schulte $\mathrm{H}$. Role of triglycerides in coronary artery disease: lessons from the prospective cardiovascular munster study. Am J Cardiol. 1992; 70: 10H-13H.

9. Austin MA. Plasma triglyceride and coronary heart disease. Arterioscler Thromb. 1991; 11: 2-14.

10. Hokanson JE, Austin MA. Plasma triglyceride level is a risk factor for cardiovascular disease independent of high-density lipoprotein cholesterol level: a meta-analysis of population-based prospective studies. J Cardiovasc Risk. 1996; 3: 213-9.

11. Gupta R, Kaul V. Prakash H, Saran M, Gupta VP. Lipid abnormalities in coronary heart disease: a population based case-control studies. Indian Heart J. 2001;52(3): 332-6

12. Pant DC, Pant H. Patterns of Extended Lipid Profile Abnormalities in Freshly Diagnosed Myocardial Infarction Patients of Bundelkhand Region. Indian J Clin Practice. 2013;23:596-600

13. Korhonen T, Savolainen MJ, Koistinen MJ, Ikäheimo M, Linnaluoto MK, Kervinen K, et al. Association of lipoprotein cholesterol and triglycerides with the severity of coronary artery disease in men and women. Atherosclerosis. 1996; 127: 213-20 